\title{
Creating the Cartographic Database and Informatization of the Systematic Cadastre Works Process
}

\author{
Elemer-Emanuel ŞUBA ${ }^{1,2}$, Tudor SĂLĂGEAN ${ }^{1,2^{*}}$, Dumitru ONOSE ${ }^{1}$, Ioana Delia POP ${ }^{2}$, Florica MATEI ${ }^{2}$, \\ Mircea ORTELECAN ${ }^{2}$, Iulia COROIAN ${ }^{2}$, Silvia CHIOREAN ${ }^{1,2}$ \\ ${ }^{1}$ Department of Topography and Cadastre. Technical University of Civil Engineering, 124 Lacul Tei \\ Boulevard, 020396, Bucharest, Romania \\ ${ }^{2}$ Department of Land Measurements and Exact Sciences. University of Agricultural Sciences and \\ Veterinary Medicine Cluj-Napoca, 3-5 Mănăştur St., 400372, Cluj-Napoca, Romania \\ *corresponding author: tudor.salagean@usamvcluj.ro
}

BulletinUASVM Horticulture 76(1) / 2019

Print ISSN 1843-5254, Electronic ISSN 1843-5394

DOI:10.15835/buasvmcn-hort: 2018.0046

\begin{abstract}
The main objective of this paper is to correlate the current cartographic database with the old one, in the systematic cadastral works. Implementing a GIS and a geodatabase containing the cartographic database is necessary for identifying the buildings in the systematic cadastral works. In order to obtain the actual mapping database, a Phantom 4 PRO drone was used, with a $20 \mathrm{mp}$ resolution camera. For determining the ground reference points there were used two South S82V GPS receivers with double frequency L1, L2, in base-rover radio mode. The existing cartographic database has been taken over from the Cadastre and Land Registration Office and integrated into the newly created geodatabase. With a unique GIS database, the process of identifying new buildings with old land data is done in a fast and efficient way. The accuracy of the new cartographic database provides greater security identifications, which can be affected even in the office, especially for those owners who have not submitted the stage of identifying the land. The exploitation of UAV photogrammetric measurements come in support of specialists carrying out systematic cadastre works, especially in the context of the low price per building imposed by the National Agency of Cadastre and Real Estate Advertising.
\end{abstract}

Keywords: geodatabase, GIS, systematic cadastre

\section{Introduction}

Taking into account the National Cadastre and Land Book Program developed by the National Agency of Cadastre and Real Estate Advertising, the realization of the cartographic database is a topical subject. The correlation of the current cartographic database with the old one is of great importance, especially because in the northern part of the country, in the area of influence of the old Austro-Hungarian Empire, there are topographic maps at scale 1: 2880, respectively old land records in which property records were made.
Considering the provisions of Law 18/1991 and later those of Law $247 / 2005$, respectively the provisions of land retrocession are in contradiction between the two laws, the first stipulating the mass restitution of the land, in the order of filing the application, and the second retrocession on the old location, integration of the old database and its correlation with the new database is absolutely necessary.

One of the turning points in terms of agricultural land was 1990, when the political regime and, implicitly, the legislative regulations changed, similarly happened in all other countries 


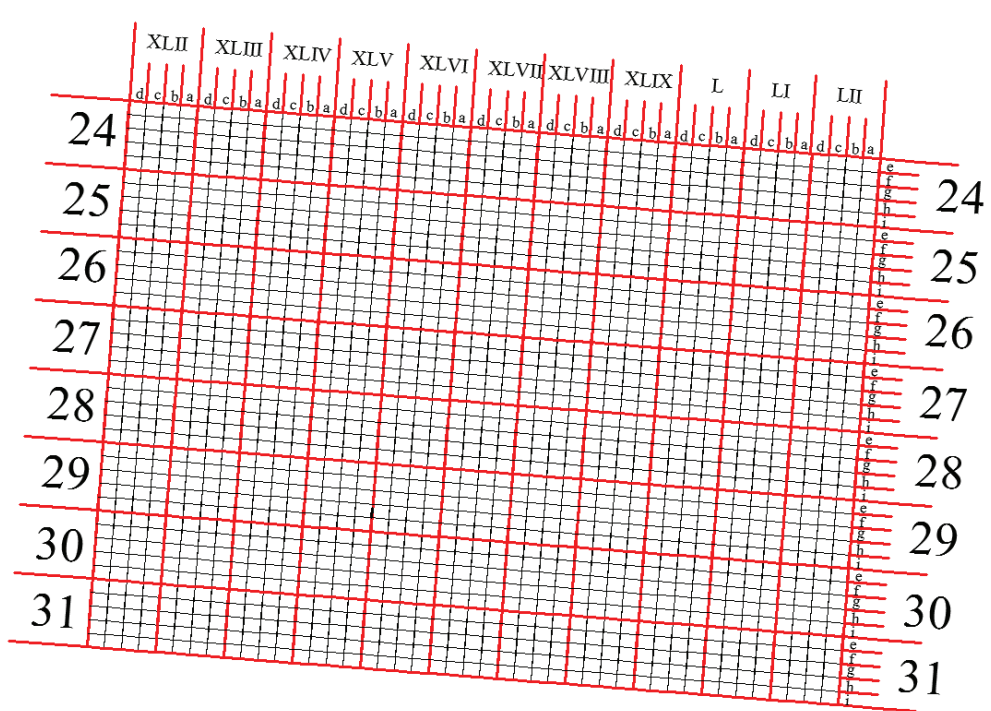

Figure 1. Nomenclature of the plans in Budapest stereographic projection

that were in the former Soviet union. Also, more distant countries like Japan are faced with similar problems (Yoshihisa, 2006)

Integration of old topographic maps into modern GIS databases requires them to be brought into the 1970 national stereographic coordinate system. This topic has been previously addressed in various studies (Timár et al., 2008). As described by Timár (2008), the georeferentiation procedure of these plans is rather laborious and it also has several shortcomings, such as the non-unitary geodetic database, the deformation of the old plans made in analog format, errors introduced when scanning old plans etc.

Also, the National Agency for Cadastre and Real Estate Publicity (ANCPI) has published specifications for scanning and georeferencing of old land book plans. Within these specifications, it is proposed to take steps to obtain the coordinates of the corner plans from the Budapest stereographic planar tangent system into stereographic 1970 projection system (Timár et al., 2003; Timár et al., 2007):

- Identifying the coordinates of the common points and of the corner plans on the Bessel ellipsoid, with the parameters expressed in fathom, in the Budapest stereographic tangent projection;

- Calculating the geographic coordinates on the Bessel ellipsoid;

- Coordinate calculation in the UTM projection of 6 degrees spindle with the local axial meridian on the Bessel ellipsoid;
- Calculating the geographical coordinates of the common points in the stereographic projection 1970 on the Krasovski ellipsoid;

- Calculating the previously mentioned coordinates in the UTM projection of 6 degrees spindle with the local axial meridian on the Krasovski ellipsoid;

- Plane transformation based on common points in the UTM projection;

- Transforming the coordinates of the corners from UTM Bessel into UTM Krasovski;

- Correlation of corners in Stereo 1970 projection;

Figure 1 shows the network 1: 2880 in stereo

Budapest, with the corners transcalculated in the Stereographic 1970 projection. The nomenclature of the plans can also be seen in the Budapest stereographic projection. These nomenclatures are presented mainly for the Maramures county.

\section{Materials and methods}

In this paper, the calculation technique was used to geo-referencing the 1: 2800 scale plans and integrate them into a GIS database. In order to achieve the topo-geodetic database we used a GPS equipment (two L1, L2, GNSS South S82V receivers with integrated radio mode) and a DJI Phantom 4 Pro UAV drone, having on board a photo camera with the following features:

20 mega pixels resolution;

1inch CMOS Sensor;

Field of View (FOV): 84ㅇ․ 8.8 mm / 24 mm (35 $\mathrm{mm}$ equivalent format);

Focal length: $\mathrm{f} / 2.8$ - $\mathrm{f} / 11$; 


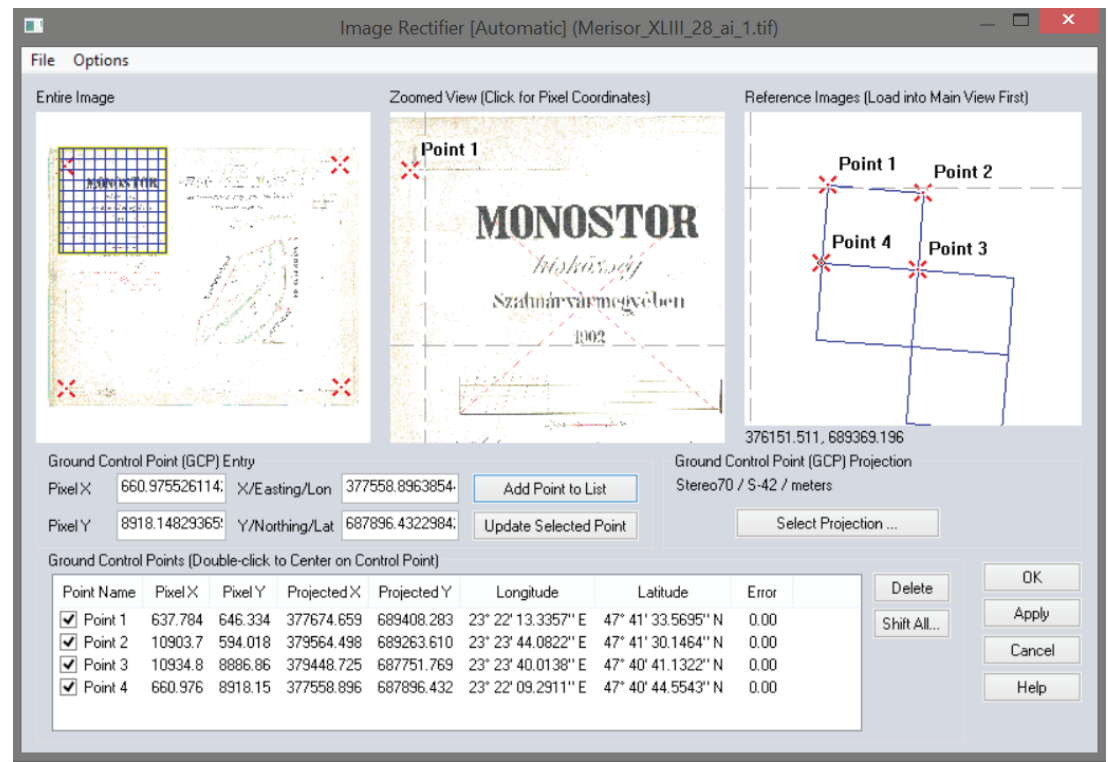

Figure 2. Georeferencing the plans

Table 1. Helmert transformation parameters

\begin{tabular}{cc}
\hline Parameter & Value [m] \\
\hline m0 & 0.241 \\
\hline $\mathrm{X} 0$ & 773.806 \\
\hline $\mathrm{Y} 0$ & 7232.007 \\
\hline $\mathrm{a}$ & 1.0000012578 \\
\hline $\mathrm{b}$ & 0.0006746469 \\
\hline $\mathrm{c}$ & -0.0006746469 \\
\hline $\mathrm{d}$ & 1.0000012578 \\
\hline Source: http://www.ocpigj.ro &
\end{tabular}

Auto Focus: from $1 \mathrm{~m}-\infty$;

ISO Range Photo: 100 - 3200 (Auto); 10012800 (Manual);

Mechanical Shutter: $\quad 8-1 / 2000$ s;

Electronic Shutter: 1/2000 - 1/8000s;

Maximum Image Size: at 3:2 ratio $(5472 \times$ 3648 pixels);

Aspect Ratio: 4:3 (4864 $\times 3648$ pixles $)$ and at $16: 9(5472 \times 3078$ pixels $)$.

Photogrammetric flights were planned using specialized software, aiming to ensure a front overlap of at least $75 \%$ and a lateral overlap of minimum 60\% (Vorovencii, 2010). All processing was done in an automated manner. Two GNSS South S82V receivers were used to determine the ground control points, in the radio-rover-base measurement mode.

To build the GIS database we started by georeferencing the 1: 2880 scale plans, in Budapest projection. The 1970 stereographic coordinates of the plans corners were calculated according to the procedure previously mentioned in the introduction. The Helmert's transformation parameters are shown in Table 1.

\section{Results and discussions}

The area taken into study is from Merisor village, Maramures county. The cadastral sectors were mainly focused on the extravilan, as ANCPI is currently financing only these works. For these reasons UAV photogrammetric elevations were made only on extravilan. A number of four plans have been identified in Merisor: XLIII 28 ai; XLIII 29 ae; XLIV 29 de; XLIV 29 df. These were georeferenced on the previously generated grid, subsequently mosaic and saved, both in color and in monochrome format, to overlay them with current orthophoto images. Figure 2 shows the georeferencing process and Figure 3 shows the mosaic of the plans.

After integrating into the database the plans 1: 2880 in Budapest projection, we started the 


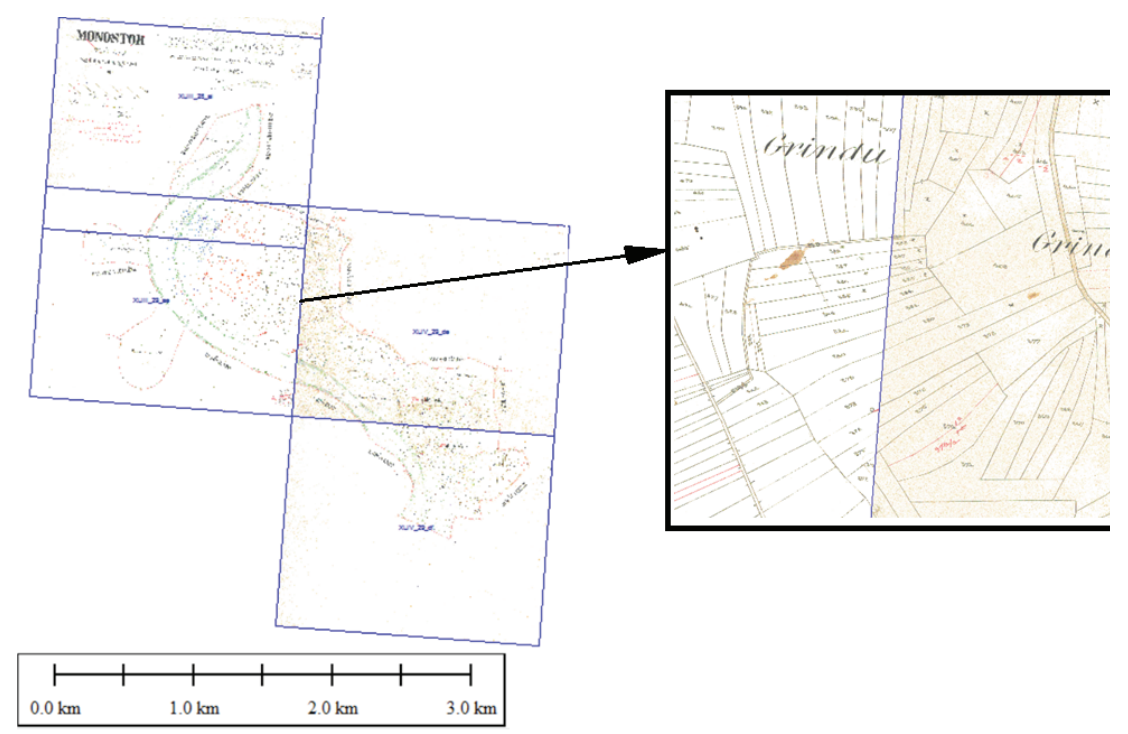

Figure 3. Mosaic of the plans

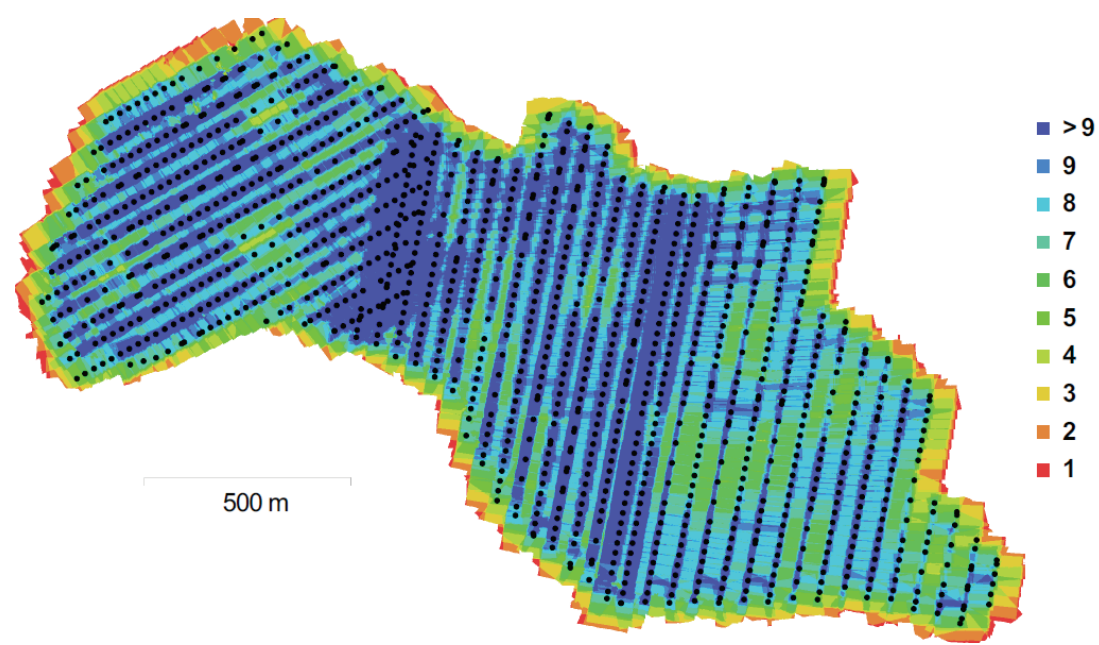

Figure 4. Camera locations and image overlap

UAV photogrammetric measurements in order to achieve the current database. For this purpose, a total of three flights were planned, covering an area of $1.99 \mathrm{~km}^{2}$. A total of 1276 photograms have been taken from an average altitude of 109 meters, with an average ground resolution of $2.69 \mathrm{~cm} /$ pixel. Figure 4 shows the flight lines, camera locations and the degree of overlapping of the photograms. It was intended to achieve overlapping of at least $60 \%$ over the entire surface.

The weakest overlap is found at the flight plan's extremes, but this does not influence the accuracy of the determinations, because at the time of planning the area has expanded more than necessary, precisely to avoid the use of orthophotomaps derived from weak overlapping photograms.
In order to ensure the quality of the georeferentiation and the integration of the orthomosaic in the 1970 stereographic projection system, as well as in the database, a number of 19 ground control points were premarked, which were evenly distributed over the studied surface. Figure 5 shows the layout of these control points, and Table 2 identifies the errors, expressed as root mean square error (RMSE) for each control point used in the photogrammetric processing.

The position of the ground control points was determined by GPS measurements, using two South S82V receivers, in the Rover Radio Base mode, with the base mounted centrally in the studied area, which ensured the precise determination of all control points. The position of the base station was determined by long static 


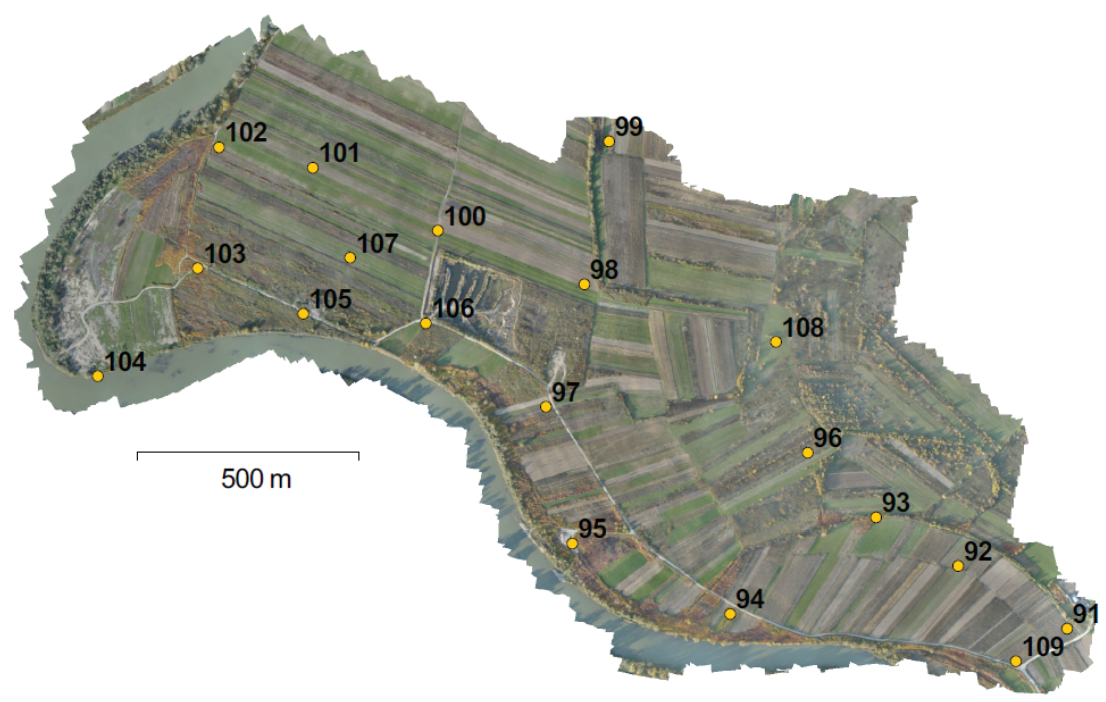

Figure 5. Ground control points location

Table 2. Errors (RMSE) for the ground control points

\begin{tabular}{cccccc}
\hline Label & XY error $(\mathbf{m})$ & Z error $(\mathbf{m})$ & Error $(\mathbf{m})$ & Projections & Error (pix) \\
\hline 92 & 0.00206753 & 0.001424750 & 0.00251090 & 6 & 0.169 \\
\hline 93 & 0.00458026 & 0.002397270 & 0.00516969 & 9 & 0.229 \\
\hline 94 & 0.00279820 & 0.000777355 & 0.00290417 & 8 & 0.164 \\
\hline 95 & 0.00418727 & -0.001256590 & 0.00437176 & 8 & 0.243 \\
\hline 96 & 0.00449364 & -0.004682520 & 0.00648990 & 9 & 0.319 \\
\hline 97 & 0.01381790 & 0.005226710 & 0.01477340 & 5 & 0.206 \\
\hline 98 & 0.01075530 & -0.003847660 & 0.01142280 & 10 & 0.405 \\
\hline 99 & 0.00720766 & 0.001994820 & 0.00747861 & 9 & 0.451 \\
\hline 100 & 0.02644530 & 0.001740370 & 0.02650250 & 16 & 0.351 \\
\hline 101 & 0.03399710 & 0.011780000 & 0.03598010 & 7 & 0.257 \\
\hline 102 & 0.02847710 & -0.009874740 & 0.03014060 & 10 & 0.237 \\
\hline 103 & 0.01633890 & 0.003867620 & 0.01679040 & 11 & 0.379 \\
\hline 104 & 0.00279630 & 0.000281315 & 0.00281042 & 8 & 0.171 \\
\hline 105 & 0.01277170 & 0.001975650 & 0.01292360 & 13 & 0.718 \\
\hline 106 & 0.00919810 & -0.009480350 & 0.01320920 & 11 & 0.243 \\
\hline 107 & 0.01909770 & -0.009773620 & 0.02145330 & 7 & 0.405 \\
\hline 108 & 0.00123315 & 0.001557490 & 0.00198657 & 5 & 0.410 \\
\hline 109 & 0.00051996 & -0.001615030 & 0.00169670 & & 0.359 \\
\hline TOTAL: & 0.01487820 & 0.005409210 & 0.01583100 & & \\
\hline
\end{tabular}

GNSS measurements. The control points were determined by measuring several epochs, with 20 determinations being performed at each point.

After obtaining the orthographic images we were able to integrate them into the database and compare the old land books with the new ones. In Figure 6, which represents the overlap between the two cartographic databases, we can say that some features have kept their approximate form, but most of the areas, due to collectivization and subsequent retrocessions based on property laws have totally changed their form.

\section{Conlusions}

As a conclusion we can express the fact that, especially in the extravilan areas, former cooperatives, where interventions were made with landscaping, drainage, road and canal creation, the relevance of the old topographical numbers is very low. Taking into account the laws of retrocession of properties, the discrepancies between their regulations and especially their differentiated application, identification on old cadastral maps is an additional control element in carrying out systematic cadastre works.

Major problems arise with the application of the provisions of Law $247 / 2005$, which allowed 


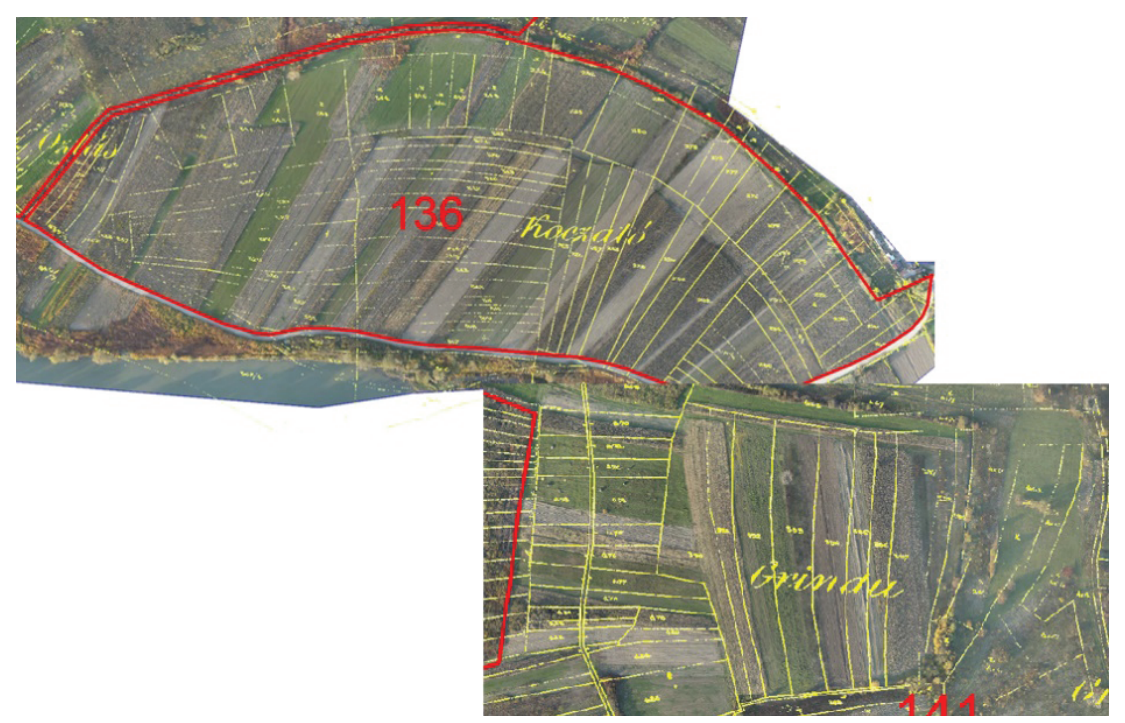

Figure 6. Overlap between the new and the old database

for the submission of additional requests for retrocession, especially for those owners, who for various reasons did not have the possibility to request them within the terms of Law 18/1991. This law provided for the restitution, on the basis of supporting documents, mainly on the old sites, but due to the previous application of the 18/1991 law, which did not take into account the old sites, many situations of conflict have occurred, many of them not being solved by courts even today.

Another impediment in the implementation of systematic cadastre works is the lack of parcel plans, or any obvious evidence on sectors or land plots of properties. Due to the chaotic retrocessions, by applying the $18 / 1991$ law, but also due to the fact that real retrocessions were made without any prior topo-cadastral measurements, many problems have been created with which the specialists involved in the systematic cadastre works are facing today.

\section{References}

1. Timár G, Molnár G, Székely B, Biszak S, Varga J, Jankó A (2008). Plans of the second topographic elevation and their georeferenced version, Journal of Geodesy, Cartography and Cadastre, 17(1-2).

2. Timár G, Molnár G, Imecs Z, Paunescu C (2007). Datum and Projection Parameters for Transilvanian sheets of the 2nd and 3rd Military surveys.

3. Timár G, Molnár G, Marta G (2003). Parameters of the Hungarian Stereographic and Zonal Cylindric projections and their datums for the GIS practice.

4. http://www.ocpigj.ro/download/2009/Ordinul\%20 DG\%20ANCPI\%2078/Scanare_\%20geogeo_\%20pl_\%20 vechi_carte\%20funciara.pdf;

5. Vorovencii I (2010). Fotogrammetrie, Matrixrom Publishing House, Bucharest.

6. Yoshihisa Godo (2006). The puzzle of small farming in Japan, Asia Pacific Economic Papers no. 365. available at https://crawford.anu.edu.au/pdf/pep/apep-365.pdf; 